Article

\title{
Participation and Goal Achievement of Multiparty Collaborative Systems Dealing with Complex Problems: A Natural Experiment
}

\author{
Petru Lucian Curșeu ${ }^{1,2, *(\mathbb{D})}$ and Sandra G.L. Schruijer ${ }^{3,4}$ \\ 1 Department of Organization, Open University of the Netherlands, 6419 AT Heerlen, The Netherlands \\ 2 Department of Psychology, Babes-Bolyai University Cluj-Napoca, 400015 Cluj-Napoca, Romania \\ 3 Utrecht School of Governance, Utrecht University, 3511 ZC Utrecht, The Netherlands; S.G.L.Schruijer@uu.nl \\ 4 TIAS School for Business and Society, Tilburg University, 5037 AB Tilburg, The Netherlands \\ * Correspondence: petru.curseu@ou.nl
}

Received: 14 January 2020; Accepted: 25 January 2020; Published: 29 January 2020

check for updates

\begin{abstract}
Multiparty collaborative systems often deal with wicked sustainability challenges. Previous research has emphasized the important role of stakeholder representation and participation in comprehensive sustainability decisions. We report the results of an empirical test of the effect of stakeholder participation on systemic goal achievement and on multiparty dynamics in a natural experiment, using the results obtained through two simulations in which 44 professionals participated. In one of the simulations a 'party exclusion dynamic' evolved. As the two simulations had a similar baseline, the same number of participants distributed in a similar manner among seven stakeholder parties in each simulation, we could test the effect of stakeholder participation on goal achievement and systemic dynamics, using the other simulation as a comparison. Our results show that stakeholder exclusion prevents systemic goal achievement, disrupts collaboration and induces systemic powerlessness.
\end{abstract}

Keywords: participation; collaboration; multiparty systems; conflict; goal achievement; inclusion-exclusion

\section{Introduction}

Sustainability challenges are often labeled as wicked problems [1,2], ranging from climate change [3], to energy transitions [4] and urban development [5]. Wicked problems have the following characteristics. First, they are ill-defined and multifaceted in that no single problem definition or problem statement can be generated and agreed upon at the onset of the problem-solving process [6]. They often contain multiple interconnected or overlapping sub-problems [7]. Second, the problem-solving process is unstructured, dynamic and complex as it should accommodate different or competing interests and divergent approaches to how the problem is to be addressed; the problem constraints may change in time as various approaches are tried out $[7,8]$. Third, wicked problems are persistent and the problem-solving process often has no stopping rule. In spite of the efforts, resource deployment and persistence of the problem solvers, the wicked problems may not actually be definitely solved [7,9]. Fourth, wicked problems usually involve various stakeholders with diverse (sometimes divergent) interests and viewpoints that are difficult to reconcile and generate different reference systems in which the problems are formulated (framed) and solutions are generated.

Given these characteristics, wicked sustainability challenges cannot be solved by individuals, groups or organizations alone, but often require the collaborative efforts of various stakeholders. As a consequence, a network approach $[7,10]$ or multiparty collaboration process $[11,12]$ have been proposed as effective ways of dealing with wicked problems. In such multiparty systems, stakeholder 
participation is key to the problem-solving approach for wicked sustainability challenges. Stakeholder participation increases the integrativeness and completeness of problem formulation. Early research on participation in environmental sustainability challenges identified three main reasons why stakeholder participation could lead to comprehensive (rational) decisions, namely substantive, normative and instrumental [13]. From a substantive point of view participation is important because it increases the amount of knowledge and expertise used to deal with sustainability challenges. From a normative perspective, stakeholder participation is aligned with democratic principles of participation. Finally, from an instrumental perspective, participation creates legitimacy for the identified solutions and reduces resistance to change when these solutions are to be implemented [13]. More recent work on the rationality of sustainability decisions emphasized the role of stakeholder participation as a means towards achieving substantive and communicative rationality of such decisions [14]. Stakeholder participation is therefore acclaimed overall as a precondition for successfully addressing wicked sustainability problems $[15,16]$. Although the literature to date abounds with studies of stakeholder participation in sustainability decisions [17], little empirical evidence exists to support the direct causal association between stakeholder participation and the collaborative success of multiparty systems.

In this paper we provide a direct test of the effects of stakeholder participation in multiparty systems on systemic goal achievement and emergence of collaboration and conflict in these systems. The setting provided in the behavioral simulation used allows for the emergence of wicked problem-like elements, as it involves a complex regional development situation (reducing water pollution, preventing and lowering unemployment, stimulating sustainable tourism and fostering economic activity) that is multifaceted with no single (best) way of dealing with the issues at hand. There are interdependencies between all stakeholders, some stronger and some less strong. In order to explore and work with these interdependencies full participation is needed. That is, all stakeholder parties should be engaged in arriving at a joint problem formulation. How this is done, which within- and between-party dynamics evolve and how these dynamics influence the problem formulation process, differs per simulation. The simulation as such provides an opportunity to experience first-hand the dynamics and complexity of collaboration. The experiential learning setting helps participants (managers and consultants) understand how group dynamics plays out in multiparty systems [18].

The current paper is based on two simulation rounds, separated by a six-month interval. They involved an equal number of participants and were based on the same structure and ground rules, yet differed in that in one simulation strong exclusion dynamics were at play. That is, two of the seven stakeholder parties were not invited to join the table in the plenary debates (incomplete stakeholder participation) while in the other simulation all stakeholders were represented in the plenary meetings (complete participation).

\section{Participation in Multiparty Collaborative Systems}

Multiparty systems are set out to deal with complex problems and decision situations. Such systems are typically composed of various stakeholders that interact in order to develop a joint problem formulation, generate solutions and make decisions [19]. In our paper we adopt the stakeholder definition as put forth by Gray and Purdy [12] who, in the context of dealing with wicked problems through multiparty systems, defined stakeholders as "all individuals, groups or organizations that can directly influence the focal problem or issue by their actions or are directly influenced by actions others take to address it" ([12], p.2). These interdependent stakeholders engage in interactions in order to collaboratively arrive at a joint problem definition, a common purpose and a problem-solving approach. Stakeholder participation and problem definition are therefore entwined, as an integrative problem definition and a comprehensive decision-making process are possible only if all stakeholders' interests are represented at the table, negotiated, discussed and ultimately integrated in the problem space $[12,17]$. Although stakeholder participation is universally acclaimed as a prerequisite for effective multiparty collaboration, literature to date lacks a systematic investigation of the causal effects of stakeholder participation on systemic goal achievement and dynamics of multiparty systems. 
Multiparty collaboration, a key process for the functioning of these social systems, refers to "the characteristic of an emerging and developing work-system of people who, because of their membership in other groups, institutions or social categories, come to work together on a largely self-constructed task or problem domain" ([20], p.164). For the purpose of this research we define the goal of such multiparty collaborative systems as the creation of a collaborative space for all stakeholders to work on a common problem definition and simultaneously find ways that their individual goals can jointly be achieved. In such systems, collaboration is emergent and builds on the interactions that unfold within groups (strategy formulation, goal setting, etc.) as well as between groups, in an attempt to develop integrative problem definitions and solutions to address these (solutions in which the interests and perspectives of all stakeholders are represented) [19,21,22]. Multiparty systems are relational spaces [16] where collaborative problem-solving may emerge. Previous research on multiparty systems explored the bottom-up and top-down relational influences in multiparty systems, showing that the within-group dynamics have an impact on the larger system while the overall systemic dynamics impact within-group interactions as well [23].

These complex dynamics are rooted in the social interdependence experienced by the stakeholders. Social interdependence theory (SIT, [24]) argues that in social interactions, two forms of social interdependence exist. Positive interdependence describes situations in which the stakeholders involved are able to achieve their individual goals only to the extent to which all other stakeholders can achieve their individual goals. Such positive interdependence is conducive for the emergence of collaborative relations and interactions. Negative interdependence, on the other hand, reflects situations in which stakeholders achieve their individual aims at the expense of the goal achievement of the other parties. Such negative interdependence leads to conflictual relations and win-lose dynamics in multiparty systems. Finally, independence means that the achievement of individual goals is not dependent on other stakeholders [24,25]. Social interdependence is at the core of multiparty system dynamics, as parties will engage in interpersonal, intra-party and inter-party interactions in function of their perceived interdependence. In other words, collaborative efforts and collaborative problem formulation attempts are driven by perceived positive interdependence, while conflictual relations are usually spurred by perceived negative interdependence.

Problem formulation in multiparty systems is often fluid, includes multiple perspectives, requires multiple resources and the commitment for action of multiple stakeholders involved [20]. Complex, multi-faceted and ill-defined problems require substantial resources, expertise and insights. Moreover, because problem formulation as well as the problem-solving approach have an emergent character and are defined though interaction, stakeholder participation is of essence in achieving collaborative synergy [21]. In an extensive analysis on various case studies of multiparty collaboration, Curșeu and Schruijer [17] emphasize the critical role of active stakeholder engagement for the success of multiparty collaboration, arguing that when parties are excluded, systemic effectiveness is compromised. Based on action research carried out in real multiparty systems, Huxham and Vangen [21] show that stakeholder representation is one of the key factors that generates collaborative advantage or inertia. They show that not involving the relevant stakeholders leads to suboptimal results or collaborative inertia, while the involvement of all relevant stakeholders generates collaborative advantage. If relevant parties participate in debates, the system engages in collaborative relations and has the potential to perform effectively, while when stakeholder diversity is suppressed, the systemic results are likely to be suboptimal [17].

If each relevant party is invited to participate and shares insights, interests and perspectives on the issue at hand, the system as a whole may thus achieve cognitive synergy and can eventually come to an integrative problem formulation $[17,23]$. Under such synergic conditions, the individual stakeholder parties can better understand the complexity of the problem at hand, while they also become aware that they depend on each other's efforts to address the problem successfully. In other words, stakeholders come to realize how they depend on others to achieve their aims (positive interdependence). They need to engage in constructive conflict as they express and deal with the various perspectives and 
interests so as to arrive at a rich and inclusive problem definition. Collaborative efforts are fostered by task disagreements that emerge when parties actively participate in the collaborative efforts and feel empowered to act.

When relevant parties are excluded from the problem definition efforts, the included ones may be (mis)led to believe that their perspective on the problem is the only or correct perspective. As argued in Curseu and Schruijer [17], if participation is low and stakeholder diversity is suppressed (relevant stakeholders are not included or their views are marginalized) the cognitive repertoire used by those who are included to tackle complex issues is limited. If the complex task is framed based on a single (or very limited) stakeholder perspective, the excluded parties may feel their interests are overlooked and ultimately experience a lack of power to influence the situation while the dominant party may erroneously assume that their problem definition is the only one, thus denying its interdependence with the other stakeholders. Although full participation is not a goal in itself, task complexity requires stakeholder involvement and working with all the interdependencies. In a fragmented system, the participating parties may experience positive interdependence among themselves but not with the ones that are excluded. Similarly, the excluded parties may experience some positive interdependence with the other excluded stakeholders and negative interdependence with the ones that dominate the collaborative efforts. Hence, fragmentation is not conducive for the emergence of systemic empowerment (stakeholders' shared perception that they have the power to influence the outcomes of the joint task formulation and resolution), as the stakeholders that participate in the problem formulation will ultimately monopolize power while the excluded stakeholders are likely to feel powerless [26]. In short, stakeholder exclusion reduces the sense of empowerment and systemic power and fosters negative interdependence and conflict in multiparty systems.

Based on the central arguments on stakeholder participation presented above and the insights from social interdependence theory (SIT), we expect that participation of all parties that have a stake in the issue fosters positive interdependence and limits negative interdependence in multiparty systems, ultimately fostering the successful addressing of the issue that the parties are confronted with. Only a wide stakeholder participation will allow the multiparty system to arrive at a problem definition that includes all relevant aspects, and ultimately allow the stakeholders to find ways to achieve their individual goals. In particular, we expect that positive interdependence, overall collaborativeness, joint sense of power and systemic goal achievements (the generation of a collaborative space in which a comprehensive problem definition is created) are higher in multiparty systems that involve all stakeholder parties in the debates than in multiparty systems that exclude stakeholders. Moreover, we expect that negative interdependence, overall conflictuality and perceived independence (each party acts on its own) are higher in multiparty systems that exclude stakeholders than in multiparty systems that do not exclude stakeholders. We set out to test these expectations in a field experiment that occurred naturally as we were running a behavioral simulation on the dynamics of multiparty relationships. We set out to explore the systemic consequences of spontaneous stakeholder exclusion by comparing two behavioral simulations run with similar ground rules, yet differentiated by the extent of stakeholder inclusion.

\section{Materials and Methods}

\subsection{Sample}

Forty-four professionals (managers and consultants, with an average age of 39.78 years) participated in two simulations as part of a business school degree program at a large Dutch business school. Each simulation had 22 participants and they were distributed in a similar way over seven stakeholder groups (in each of the two simulations) according to their expressed preferences. No individual roles were formally assigned to participants; they were only asked to identify as much as possible with their stakeholder's interests. 


\subsection{Procedure}

The behavioral simulation is a learning exercise to help participants gain experience with the dynamics of multiparty interactions [20,23]. The simulation lasted two days, with the simulation itself covering the first day and the morning of the second day, followed by a debriefing and joint sense-making for the remainder of the second day. Two facilitators (the authors) observed the withinand between-group interactions during the simulation and offered feedback in the debriefing based on their observations and based on the survey results that participants were asked to complete at three times during the simulation.

The simulation describes a complex issue of regional development around the island of Kotlin in the Gulf of Finland [20]. Seven stakeholders are involved and they do not receive any framing on how they are to define the problem and to engage in solution finding. They are not asked to deliver a solution-it is up to the participants to decide how they use their time. The general information portrays various complex issues associated with the reduction of governmental subsidies for the local economy, water pollution and unemployment that lead to the emergence of wicked problem-like elements that the seven stakeholders have to address. The first stakeholder is the shipyard, the most important employer on the island facing massive layoffs due to the dramatic decrease in orders from their most important client, the navy. The shipyard interest is to regain their profitability. Public authorities are the second stakeholder and they are facing serious socio-economic and environmental challenges due to the looming unemployment and the severe pollution of the sea surrounding the island. Three yacht clubs have each their own economic interest: an island-based yacht club intends to expand its business, boat and customer base, a yacht club based in St Petersburg with access to lakes with clean water on the mainland and a yacht club from Finland with an interest to partner with Russian yacht clubs and expand their regional reach. The last two parties are a bank interested in long-term investments and a club of private investors-rich entrepreneurs focused on obtaining short-term profits. Each of the seven stakeholders has their own perspective, interests and representation of the "problem space" and can interact with the other stakeholders to come to a joint problem formulation and find plausible ways to deal with the issues at hand (or not). At the onset of the simulation participants receive detailed brochures describing the situation in general terms and describing the perspective and interests of their own party in particular (for more details see [20].

Parties also received information on the various challenges the region faces, ranging from environmental problems to social and economic ones, making the simulation a context in which elements of wicked-like sustainability problems easily emerge. The two facilitators do not interfere in any way with the dynamics of the simulation. Each stakeholder group is informed that they can talk to the other groups during so-called visiting times (with a maximum of three groups or representatives of three groups being allowed to be present at the same time in the same room) and during the town hall meetings in which each of the seven stakeholders can delegate a representative to the table (the remaining members can sit behind them and communicate with their representatives via notes). At the onset of the simulation the facilitators present the agenda in which the time intervals for visiting and town hall meetings are specified. Except for this time structure and a few ground rules for interaction the participants are fully in charge of the process. Usually the public authorities, one of the parties, take the initiative to organize the town hall meetings and invite the stakeholders to attend these meetings during the first visiting session. In one of the two simulations the public authorities only invited two other parties to attend the first town hall meeting and did not invite two of the stakeholders to any of the five town hall meetings. This particular dynamic created a "natural experiment" setting that allowed us to compare the results of the self-reports on social interdependence and systemic dynamics as they evolved in the two simulations.

The participants were asked to fill out surveys at three points in time and the results of these surveys were used as part of the debriefing session during the second day. The first survey asked participants to express their expectations about the simulation dynamics and was filled out after the groups read the information presented in the booklets and prepared their strategy in a first within-group 
meeting (yet before any intergroup interaction). In other words, the first survey captured participants' expectations for within-group as well as between-group interactions. The second survey was filled out after the intergroup interactions started, namely after the second town hall meeting (it captured participants' experiences of intergroup interactions) and the third survey was filled out at the end of the last town hall meeting and assessed the participants' experiences at the end of the simulation. This distribution of the surveys allowed us to establish a baseline (surveys filled out at time 1 capturing expectations and those filled at time 2 capturing perceptions after initial interactions) and then compare the two simulations at time 3 after the simulation ended. The number of participants was equal in both simulations and the simulation structure was the same, therefore systematic differences that are observed at the end of the simulation are likely to at least partially reflect the impact of differentiated stakeholder participation in the two simulations.

\subsection{Measures}

Social interdependence was evaluated with three items capturing the three forms of interdependence described by Deutsch [24], namely positive interdependence ("my interest party can achieve its interests only if the other parties achieve their own interests-we will gain only if others will gain as well"), negative interdependence ("my interest party can achieve its interests only at the expense of the other parties-we will gain more only if others will gain less") and independence ("my interest party can achieve its interests on its own-we do not need the other parties"). Answers were recorded on a five-points Likert scale (1-fully disagree to 5 -fully agree).

Systemic power was evaluated using a round robin procedure and each participant was asked to evaluate the power for their own party as well as for all the other parties in the simulation ("please evaluate how much power you think each of the parties has. The evaluations range from 0 -No power at all to 5-a very powerful party"). The evaluations received for all parties were averaged to get an indication of the systemic power perceived by participants in each of the two simulations.

Systemic collaborativeness was also evaluated using a round robin procedure and the participants were asked to evaluate the collaborativeness of their own party and each of the other parties as well ("please evaluate how collaborative you think each party will be/is/was. The evaluations range from 0 -not collaborative at all to 5-very collaborative"). As for power, the answers were aggregated across parties in the simulation in order to obtain a generic indicator of systemic collaborativeness, per simulation as perceived by each participant.

Systemic conflictuality was evaluated using a round robin procedure and the participants were asked to evaluate how conflictual they perceived each stakeholder party to be ("please evaluate how conflictual you think each party will be / is / was. The evaluations range from 0 -not conflictual at all to 5-very conflictual"). Scores were aggregated across parties to obtain an overall score of conflictuality for each of the two simulations.

Systemic goal achievement was also evaluated using a round robin technique and each participant was asked to evaluate the extent to which each stakeholder party achieved their goal during the simulation (at the onset of the simulation, we evaluated the expectations of goal achievement) ("do you think the interest parties (including yours) will achieve/achieved their goals so far/in the end? The evaluations range from 0 -not at all to 5 -completely"). Scores were aggregated across parties to obtain a systemic indicator of goal achievement in each of the two simulations as perceived by each participant.

Participant observation notes were used to back up some of the interpretations derived from analyzing the quantitative data. Two observers (the authors) took detailed notes during the multiparty interactions (both in the visiting as well as the plenary meetings). From these notes that included verbatim statements made by participants during interactions, we selected a number of quotes in order to further illustrate the results. 


\section{Results}

Data was analyzed using MANOVA (multi-variate analysis of variance) with the two simulations as a factor (complete versus incomplete stakeholder participation) and the three types of social interdependence, systemic collaborativeness, conflictuality, power and goal achievement as dependent variables. The MANOVA results are presented in Table 1. They reflect the comparison between the participants in the two simulations (complete versus incomplete participation). The first column (expectations) reflects the baseline condition in that participants shared their expectations in the absence of any intergroup interactions, the second column reports comparisons after initial interactions started while the results in the last column reflect the outcomes at the end of the simulation.

Table 1. MANOVA results comparing the two simulations.

\begin{tabular}{|c|c|c|c|}
\hline & Expectations (Time 1) & $\begin{array}{l}\text { During Interactions } \\
\text { (Time 2) }\end{array}$ & $\begin{array}{l}\text { At the End of the } \\
\text { Simulation (Time 3) }\end{array}$ \\
\hline $\begin{array}{c}\text { Negative } \\
\text { interdependence }\end{array}$ & $\begin{array}{c}\mathrm{F}(1,42)=2.46(p=0.12) \\
\eta^{2}=0.05, \pi=0.33\end{array}$ & $\begin{array}{c}\mathrm{F}(1,42)=0.02(p=0.87), \eta^{2} \\
=0.00, \pi=0.05\end{array}$ & $\begin{array}{c}\mathrm{F}(1,42)=0.01(p=0.90), \eta^{2} \\
=0.00, \pi=0.05\end{array}$ \\
\hline Positive interdependence & $\begin{array}{c}\mathrm{F}(1,42)=0.13(p=0.71) \\
\eta^{2}=0.00, \pi=0.06\end{array}$ & $\begin{array}{c}\mathrm{F}(1,42)=0.28(p=0.59), \eta^{2} \\
=0.00, \pi=0.08\end{array}$ & $\begin{array}{c}\mathrm{F}(1,42)=4.40(p=0.04) \\
\eta^{2}=0.09, \pi=0.53\end{array}$ \\
\hline Independence & $\begin{array}{c}\mathrm{F}(1,42)=0.00(p=1.0), \eta^{2} \\
=0.00, \pi=0.00\end{array}$ & $\begin{array}{c}\mathrm{F}(1,42)=0.02(p=0.88), \eta^{2} \\
=0.00, \pi=0.05\end{array}$ & $\begin{array}{c}F(1,42)=4.25(p=0.04) \\
\eta^{2}=0.09, \pi=0.52\end{array}$ \\
\hline Systemic power & $\begin{array}{c}\mathrm{F}(1,42)=0.48(p=0.48) \\
\eta^{2}=0.01, \pi=0.10\end{array}$ & $\begin{array}{c}\mathrm{F}(1,42)=2.31(p=0.13), \eta^{2} \\
=0.05, \pi=0.31\end{array}$ & $\begin{array}{c}\mathrm{F}(1,42)=4.21(p=0.04) \\
\eta^{2}=0.09, \pi=0.51\end{array}$ \\
\hline $\begin{array}{c}\text { Systemic } \\
\text { collaborativeness }\end{array}$ & $\begin{array}{c}\mathrm{F}(1,42)=0.06(p=0.80) \\
\eta^{2}=0.00, \pi=0.05\end{array}$ & $\begin{array}{c}\mathrm{F}(1,42)=0.12(p=0.72), \eta^{2} \\
=0.00, \pi=0.06\end{array}$ & $\begin{array}{c}\mathrm{F}(1,42)=4.20(p=0.04) \\
\eta^{2}=0.09, \pi=0.51\end{array}$ \\
\hline Systemic conflictuality & $\begin{array}{c}\mathrm{F}(1,42)=1.40(p=0.24) \\
\eta^{2}=0.03, \pi=0.21\end{array}$ & $\begin{array}{c}\mathrm{F}(1,42)=2.20(p=0.14), \eta^{2} \\
=0.05, \pi=0.30\end{array}$ & $\begin{array}{c}\mathrm{F}(1,42)=0.15(p=0.69), \eta^{2} \\
=0.00, \pi=0.06\end{array}$ \\
\hline $\begin{array}{l}\text { Systemic goal } \\
\text { achievement }\end{array}$ & $\begin{array}{c}\mathrm{F}(1,42)=1.54(p=0.22) \\
\eta^{2}=0.03, \pi=0.22\end{array}$ & $\begin{array}{c}\mathrm{F}(1,42)=10.23(p=0.003) \\
\eta^{2}=0.19, \pi=0.87\end{array}$ & $\begin{array}{c}F(1,42)=14.18(p=0.001) \\
\eta^{2}=0.25, \pi=0.95\end{array}$ \\
\hline
\end{tabular}

As indicated by the MANOVA results presented in Table 1, at the onset of the simulation, no significant differences were obtained between the two simulations for any of the dependent variables considered in the study. This first set of analyses reflects the common baseline for the two simulations, supported by the fact that in terms of expectations, the participants did not differ significantly in the two simulations. For the second round of evaluations, the same pattern of results is observed, showing that after the second town hall meeting, the two simulations did not differ significantly in the experienced social interdependence, systemic power, conflict and collaborativeness. The exception is systemic goal achievement for which we observed significant differences, $\mathrm{F}(1,42)=10.23(p=0.003)$, $\eta^{2}=0.19$, observed power $\pi=0.87$, showing that participants in the simulation that excluded parties from the town hall meetings reported a significantly lower systemic goal achievement $(\mathrm{M}=1.55$, $\mathrm{SD}=1.16$ ) than participants in the simulation that did not exclude any stakeholder parties from the town hall meetings $(\mathrm{M}=2.50, \mathrm{SD}=0.74)$. At the end of the simulation significant differences were obtained for all dependent variables with the exception of negative interdependence and systemic conflictuality. That means the two simulations did not differ significantly in the extent to which participants perceived negative interdependence and conflict in the simulation. The participants in the simulation that excluded the parties from the town hall meetings reported significantly lower positive interdependence $(\mathrm{M}=3.00, \mathrm{SD}=1.15)$ and higher independence $(\mathrm{M}=2.09, \mathrm{SD}=0.92)$ than participants in the simulation that did not exclude stakeholder parties from the town hall meetings (for positive interdependence $\mathrm{M}=3.68, \mathrm{SD}=0.99$ and for independence $\mathrm{M}=1.59, \mathrm{SD}=0.66)$. Moreover, participants in the simulation that excluded stakeholders reported less overall systemic power $(\mathrm{M}=2.47, \mathrm{SD}=0.71)$ and lower collaborativeness $(\mathrm{M}=2.57, \mathrm{SD}=1.05)$ than participants in the simulation that did not exclude stakeholders (for systemic power $\mathrm{M}=2.85$ and $\mathrm{SD}=0.51$, and for collaborativeness $\mathrm{M}=3.09$ 
and $\mathrm{SD}=0.54)$. Finally, the greatest difference was observed for systemic goal achievement, in that participants in the simulation that excluded stakeholders reported lower levels of systemic goal achievement $(\mathrm{M}=2.31, \mathrm{SD}=1.02)$ than participants in the simulation that did not exclude stakeholders $(\mathrm{M}=3.25, \mathrm{SD}=0.55)$. As also indicated in the trends depicted in Figure 1 Figure 2 Figure 3 Figure 4 Figure 5 Figure 6 Figure 7, in general, the results supported our expectations with the exception of negative interdependence and conflict.

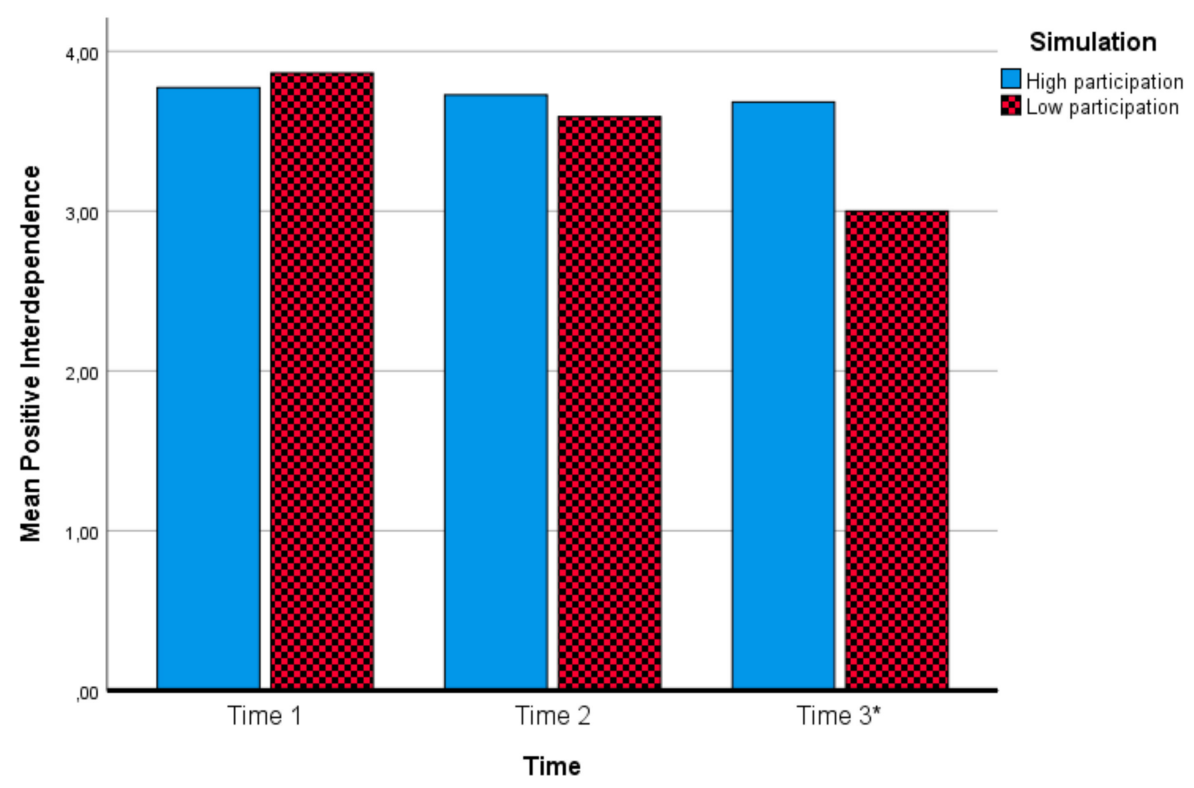

Figure 1. Means of positive interdependence in the two simulations across time (* mean difference is significant at $p<0.05)$.

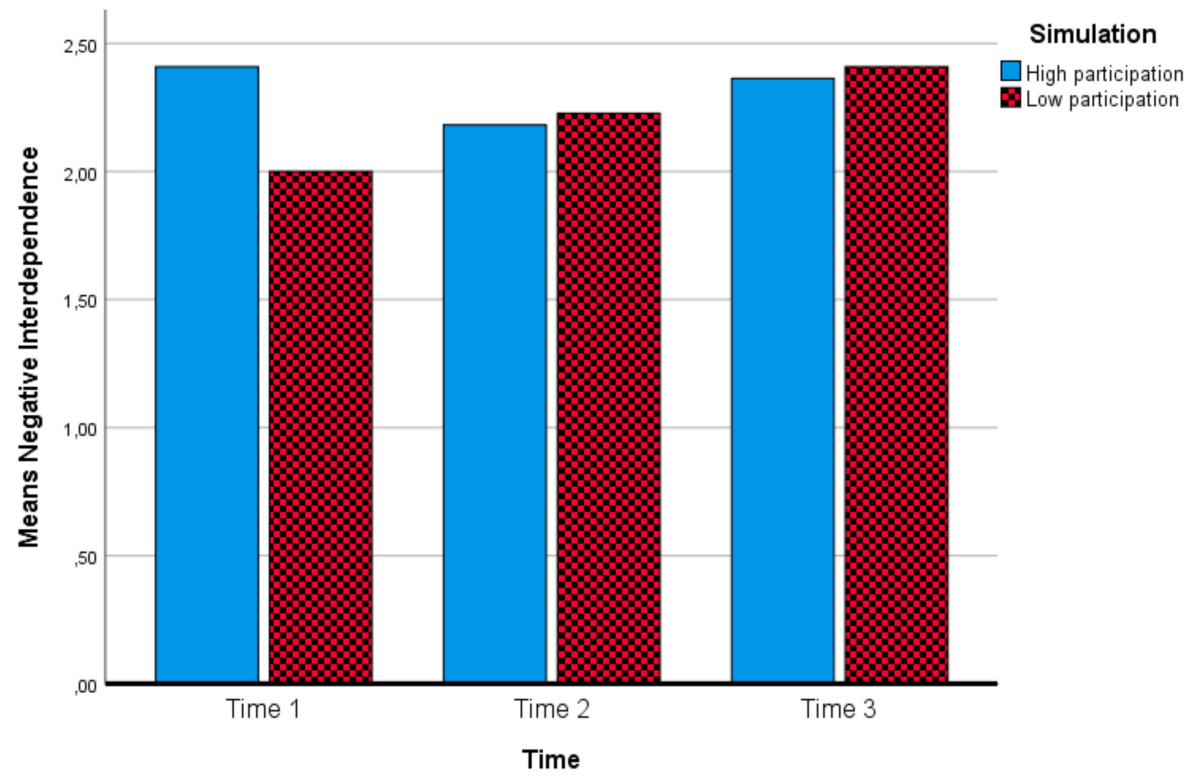

Figure 2. Means of negative interdependence in the two simulations across time. 


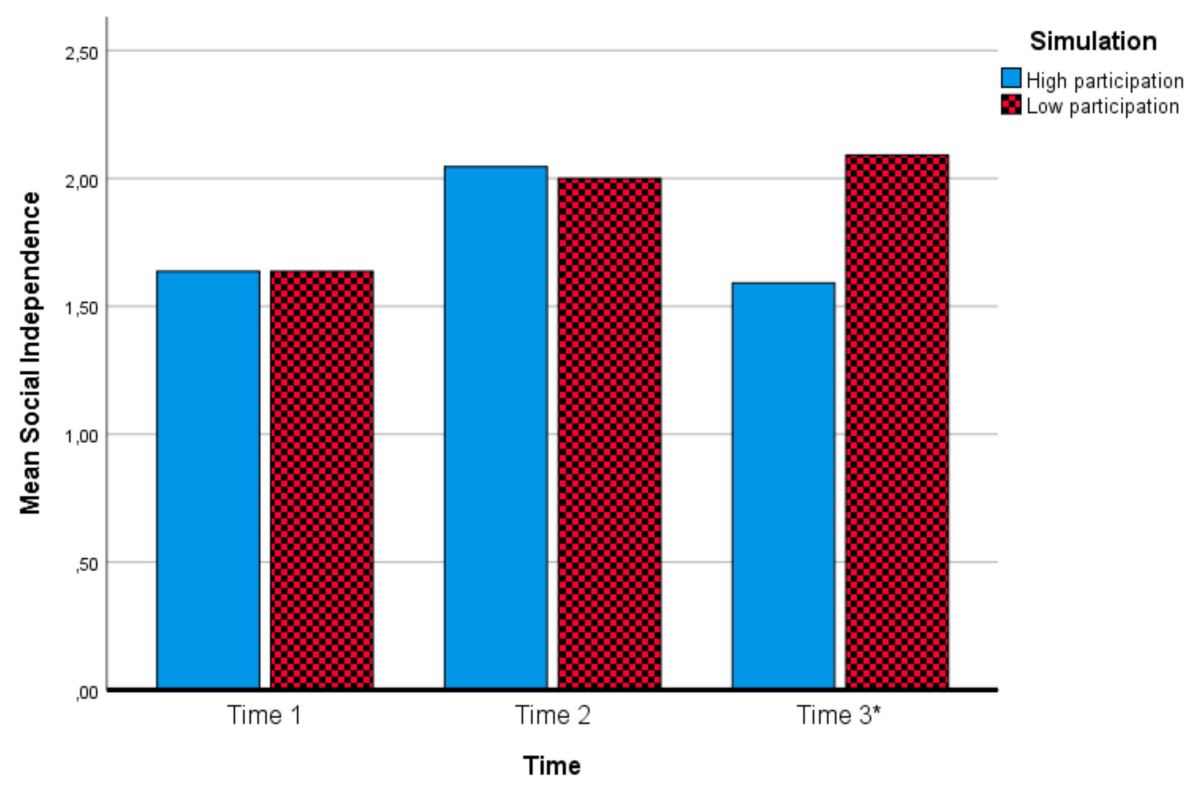

Figure 3. Means of social independence in the two simulations across time $\left({ }^{*}\right.$ mean difference significant at $p<0.05)$.

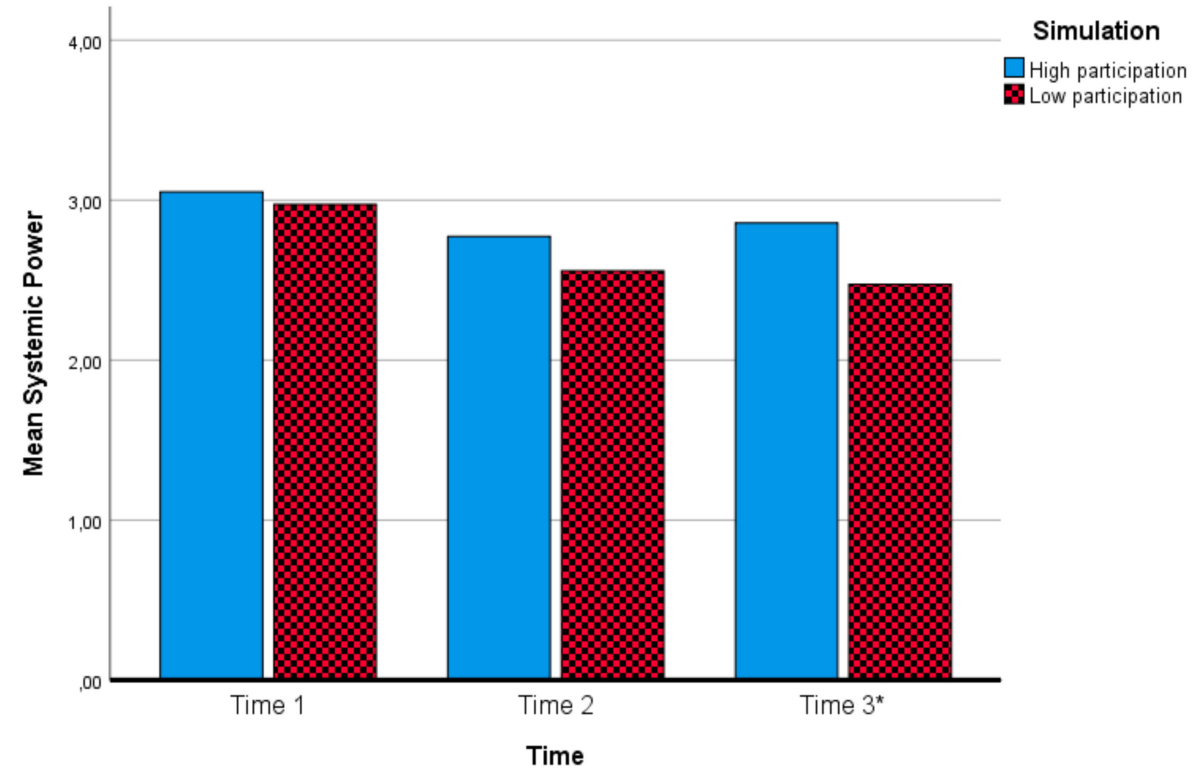

Figure 4. Means of systemic power in the two simulations across time ( ${ }^{*}$ mean difference significant at $p<0.05)$. 


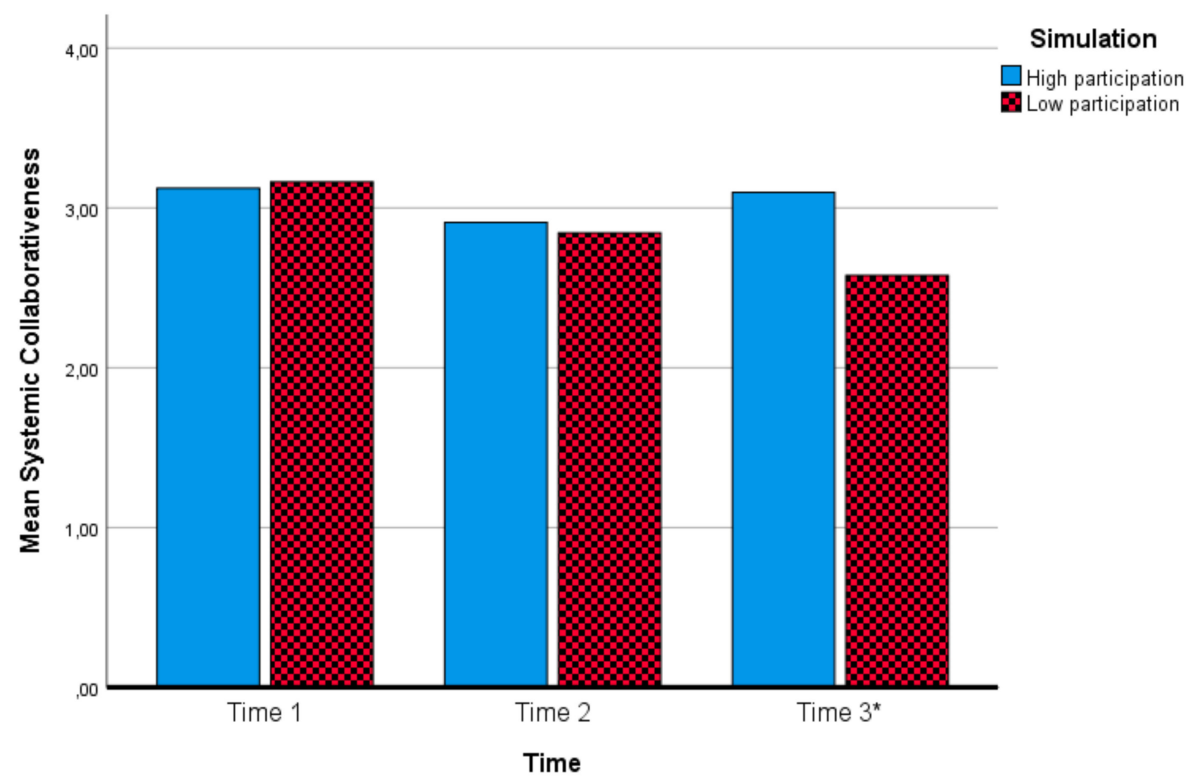

Figure 5. Means of systemic collaborativeness in the two simulations across time (* mean difference significant at $p<0.05)$.

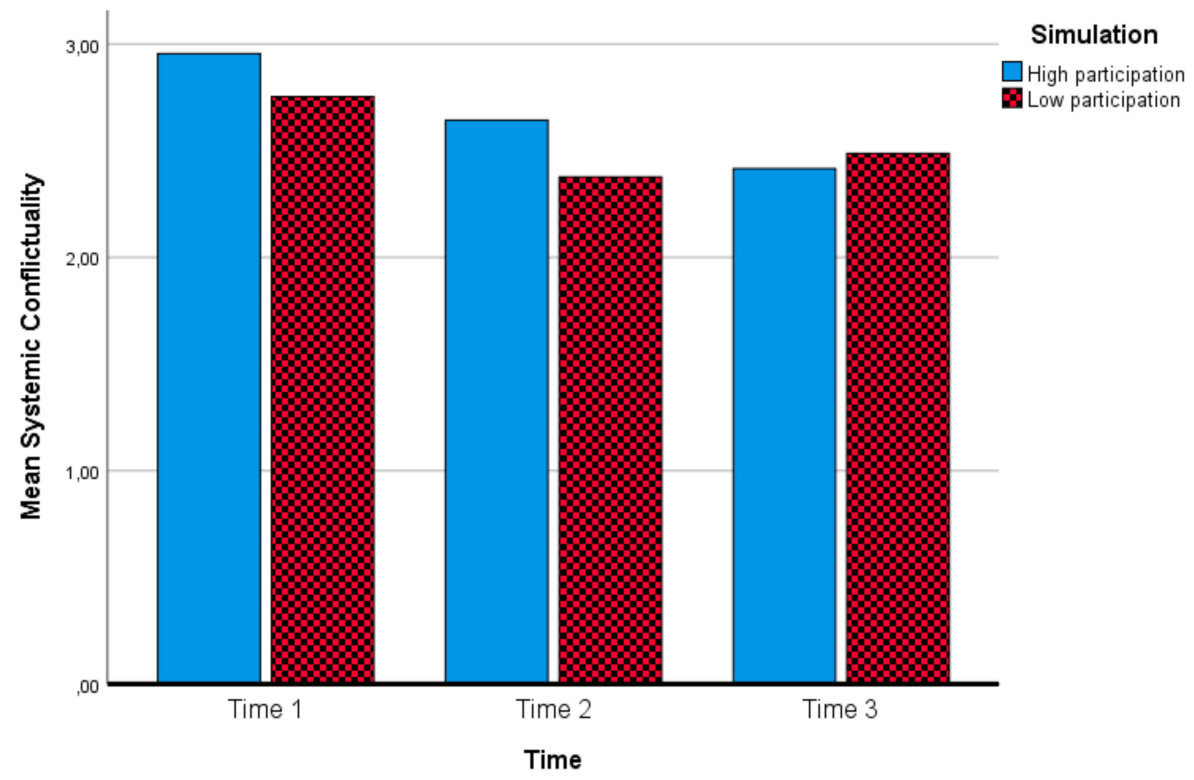

Figure 6. Means of systemic conflictuality in the two simulations across time. 


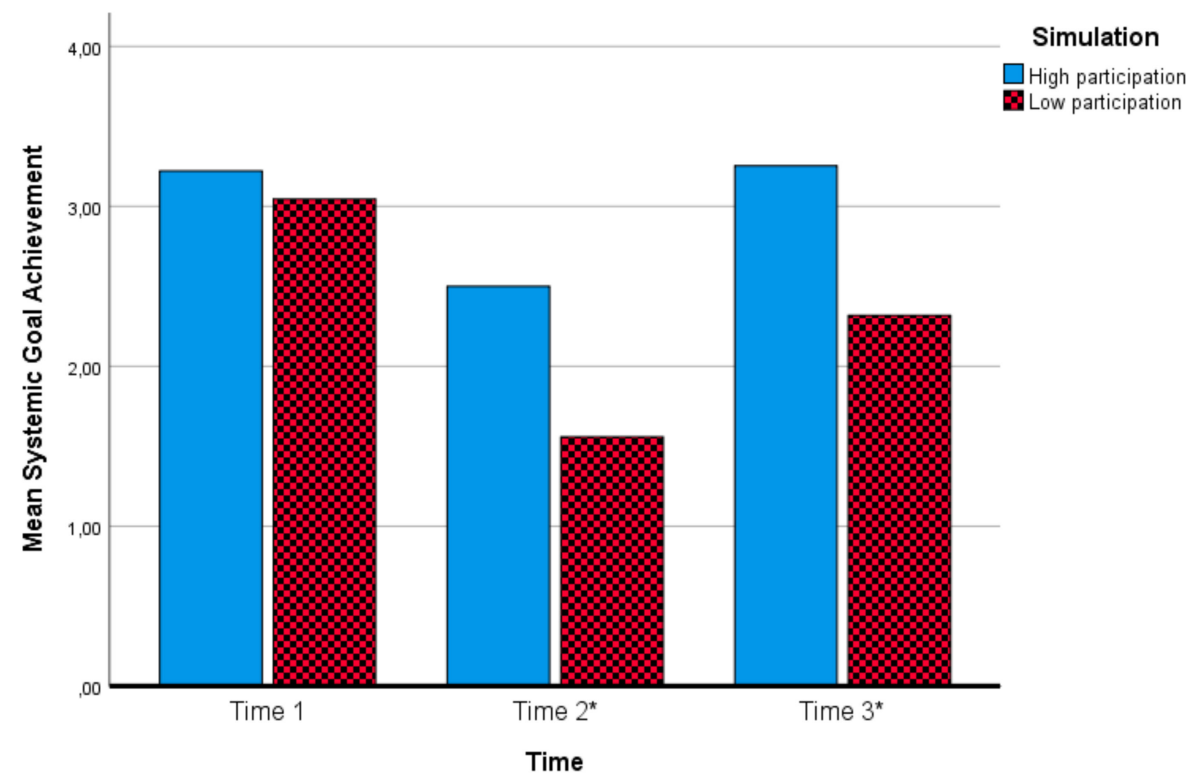

Figure 7. Means of systemic goal achievement in the two simulations across time (* mean difference significant at $p<0.01)$.

\section{Discussion}

Our paper reports one of the first empirical studies that directly test, in an experimental design, the causal association between stakeholder participation and collaborative success in multiparty systems. The natural experiment setting was created by the fact that the public authorities excluded relevant stakeholders in one of the two simulations. Although the public authorities do not have a formal leadership role in the simulation, this party takes the lead in inviting the participants to the town hall meetings. Excerpts from their internal discussion reveal their exclusive invitation strategy in one of the simulations: (member 1) "there are five meetings. How to invite? A party per meeting?"; (another member) "first where the need is highest. Shipyards"; ... (member 1) "we invite for the common good. Is everyone welcome, that is the question. I do not want the rich ones. Do we want a 'Poolse landdag' [unstructured, chaotic meeting-PC and SS]? Or first the big parties. And those with whom we already have a collaboration: shipyards and Kronshtadt [the yacht club on the island-PC and SS]. What do we do with Finlandia? Already in this phase at the table? So first the island-bound parties?"; (another member) "yes the biggest! Shipyards and Kronshtadt. With those we have a relationship. We will ask Kronshtadt to start a relationship with MBP and Finlandia [the yacht clubs located outside the island-PC and SS]). How realistic is it that yacht clubs sit at the table with public authorities?" At the end of another internal meeting of the public authorities one member concluded: "I already told the other parties how we are going to deal with it. If we do it differently, it is not reliable. Whom do we invite? Shipyards and Kronshtadt. And then together we will explore who else". Eventually, the first town hall of this simulation started with just three parties at the table (the public authorities, the shipyard and the island yacht club) and at the subsequent town hall meetings two stakeholders were never invited, namely the two yacht clubs located outside the island. In the other simulation, all parties were invited to attend all five town hall meetings. This difference in participation created a natural experiment in which we could explore the causal association between stakeholder participation and the collaborative success of multiparty systems. 
Our results support the positive effect of stakeholder participation on positive social interdependence and in general did not support a significant effect of stakeholder participation on negative interdependence. The fact that the participants in the simulation that excluded relevant stakeholders did not report more negative interdependence and systemic conflictuality than the ones in the simulation with full participation could be explained by the fact that stakeholder exclusion artificially reduced conflict around the table and the perception of negative interdependence. The most notable effect of stakeholder exclusion was on systemic goal achievement. Already in the second survey, after the second town hall meeting, participants in the simulation that excluded parties from their task formulation and problem-solving efforts reported lower goal achievement than the participants in the simulation in which all stakeholders were included. This difference was further accentuated at the end of the simulation. Shortly put, stakeholder exclusion prevents all parties involved from achieving their aims.

This result goes hand in hand with a systematic decrease over time of reported positive interdependence observed in the simulation that excluded stakeholders, while in the simulation in which all stakeholders participated in the town hall meetings the perception of positive interdependence was rather stable in time (see Figure 1). If stakeholders fail to realize that they need each other in order to come up with a joint task definition and problem framing, the multiparty system cannot generate a comprehensive analysis of the situation and the problem formulation includes only the interests of the parties present at the table. This is reflected in one of the statements of the public authorities in the first town hall attended by the shipyard and yacht club on the island: "we need to see from a public perspective how things work out as what we are facing is an important public issue for the island. Then we need to decide how to move forward and how we can involve the others". This statement already formulates the joint problem as an "island issue" and excludes the "non-islander" stakeholders-an island framing excluded the regional players from the beginning and thus prevented the parties from fully exploring all possible interdependencies. This framing can be rather persistent as at the onset of the second town hall, the public authorities started with the following opening statement: "welcome all to our second meeting in which we should discuss about the future of our wonderful island". This framing illustrates the reduction of the regional focus to a restricted focus on the island alone.

The exclusion of relevant stakeholders reduces empowerment as illustrated by the fact that systemic power decreases constantly over time in the simulation in which relevant stakeholders were excluded (see Figure 4). Lack of perceived power reduces the agency that the stakeholders have in dealing with the task. When only some of the stakeholders are represented in the town hall, the excluded participants can only watch from the sidelines how the protagonists at the table attempt to generate a shared problem definition. Most certainly this generates a sense of powerlessness and helplessness in dealing with the task. A short discussion in the group representing the bank right after the first town hall in which they did not participate reflects this aspect: "(member 1) I would have liked to participate in the town hall; (member 2 ) yes, but they have sent us away, who are public authorities anyway?; (member 2 ) the public authorities is a very powerful party as they give permits if companies want to develop business on the island; (member 1) yes, but we as a bank also evaluate plans; (member 2) so should we participate in the next town hall meeting?; (member 1) no, I think we should follow it from the audience; (member 2) but this will exclude us from the plans that are made and I think we are here to take part in the town hall meetings as well; (member 1) in the town hall meeting no clear deals will be made among the parties anyway".

This dynamic ultimately breaks the integrity of the system as illustrated by the systematic increase of social independence illustrated in Figure 3. A system in which parties perceive their interests to be independent cannot generate a collaborative setting in which comprehensive understanding of the situation at hand can be produced. The decrease of systemic collaborativeness (see Figure 5) in time also supports this claim. True collaboration only emerges in the presence of task conflict. Parties have to engage with each other and explore their interdependencies in order to build the relational synergy that ultimately will help them formulate the problem and find solutions [17]. The process of 
finding a joint goal or a shared problem definition is not easy even when all stakeholders participate. As illustrated in Figure 7 the evaluations of goal achievement drop from time 1 to time 2 for both simulations (more accentuated in the case of the simulation with low participation), showing that when parties start talking to each other and discover the complexity of their interdependencies, the initial expectations concerning goal achievement recede. In other words, if initially all stakeholders in both simulations believe there is a reasonable chance they will achieve their aims, after the second town hall, when complexity sets in, goal achievement scores drop significantly, and this drop is more accentuated in the simulation in which stakeholders were excluded from the town hall meetings. It is only at time 3 when parties have managed to explore more fully their interdependencies that evaluations of goal achievement increase again, for the simulation with full participation to a much larger extent than for the simulation with low participation.

Although the practical implications of these results are straightforward, stakeholder participation is not easy to achieve. Stakeholders have to understand the value of sharing their insights, interests and assets and thus possibly becoming vulnerable to the actions of others. Coping with a diversity of interests and opinions is difficult and the emerging complexity may push stakeholders to believe that it is too difficult if not impossible to generate a joint problem definition, and as such they tend to focus on their individual goals or to reduce the complexity by focusing on partnering with just a few other stakeholders. Such an explanation is supported by the systematic decrease in systemic conflictuality and the increase in perceived independence. Parties seem to drift apart as the simulation evolves, to focus on simpler, more manageable collaborative relations that ultimately prevent them from achieving greater systemic collaborative goals. It is important to create awareness of such dynamics in multiparty systems, in order to support full participation and to prevent the detrimental effects of systemic fragmentation.

\section{Limitations and Future Research Directions}

Our paper has several limitations. First, we have used a natural experiment setting to make a comparison between two simulations that differed in how stakeholders were involved in the multiparty task. Although the baseline with respect to the dependent variables that we have evaluated show no systematic differences between the two simulations at the onset, it is possible that there have been additional factors that have impacted the scores on the dependent variables that we did not account for in our analyses. Second, the sample size is rather limited as only 44 professionals took part in our study. Based on a G-power estimation for a design such as ours (with an expected power of 0.95 and $\alpha=0.05)$, the estimated total sample size is 46 participants. In our paper we report a natural experiment, therefore we could not influence the total sample size, yet the sample size used in our study is not far from the required sample size estimated using G-power. Nevertheless, future research should attempt the replication of these results using larger samples and potentially in other settings as well. Third, we have used a behavioral simulation that relies on a particular context and task (a regional development issue) and beyond the benefits of using the same task structure and the same stakeholders for the sake of comparison, we have to also acknowledge that the specific task used is a boundary condition and limitation of our study. Fourth, our study took place in a naturalistic setting in which the "manipulation" occurred naturally and we had to rely on a between-participants experimental design. In such a design individual differences may play a role in how individuals engage in social interactions and these differences could be an alternative explanation of our findings. However, in line with social interdependence theory, expectations are the roots of social interactions [27]. Thus in social settings individuals behave in line with their interpersonal expectations of positive or negative interdependence. In our study the baseline shows that the participants in the two simulations did not differ in their expectations at the onset of the simulation. Moreover, at time 2, after the interactions started, the differences in the dependent variables (with the exception of systemic goal achievement) were still not significant as illustrated by the results presented in Table 1 . Therefore, we can state that both simulations have similar starting points with respect to expectations and initial interactions. 
Future research could however use within-participant designs to fully account for the potential effects of individual differences. Another boundary condition refers to the stakeholders to be included in the multiparty system and the way they are selected in real-life settings. Our study allowed us to control for this aspect as the same stakeholders were represented in the two situations and they had similar instructions and ground rules for interaction. Stakeholder selection, however, is a key issue that will influence participation in the later stages of collaboration. As we have argued, collaboration is an emergent phenomenon in such complex systems and the characteristics of the task are likely to impact on how collaborative synergies are created.

\section{Conclusions and Practical Implications}

Our paper has important theoretical and empirical implications for the exploration of stakeholder participation in multiparty systems. It is one of the first empirical papers to probe the causal association between stakeholder participation and collaborative success in multiparty systems. Literature to date focused on non-experimental studies (based on surveys and case studies) that cannot fully account for the causal role of stakeholder participation in collaborative success in multiparty systems. Our results further support the claim that stakeholder participation is a precondition for achieving substantive rationality in sustainability decisions [14,17]. Moreover, we bring further support for the social interdependence theory by showing that stakeholder participation has opposite effects on the two forms of interdependence as described in SIT. As stipulated in SIT incomplete participation decreases positive interdependence and increases negative interdependence, ultimately preventing the system to achieve its collaborative goals. In line with previous claims $[28,29]$ our paper advocates the integration of theories from social and applied psychology with the ones emerging in the field of sustainability in order to better understand the dynamics of collaboration in multiparty systems dealing with sustainability challenges.

Our results also have important implications for policy makers. When facing the challenges of wicked problems, multiparty collaboration is imperative and wide stakeholder participation is of essence. We are aware that in real-life collaborative settings, deciding on stakeholder representation is not a trivial task [21]. The selection of relevant stakeholders should ensure sufficient resources, expertise and insights into the task at hand in order to generate an integrative problem formulation. Moreover, the participation of representatives should be balanced in terms of status differences in order to make sure that the diversity of views and interests is actually expressed [17,21]. Although the regional development concern in the simulation does not depict a wicked problem per se, the emergent problem-solving process has the potential of becoming wicked as group dynamics often complicate the rational analysis of the situation at hand. The policy implications speak to multiparty systems and may also have implications for particular cases of wicked problems. It is important to make sure that stakeholder representation and participation is as complete as possible. Multiparty facilitators can support the increasing complexity as a consequence of wider stakeholder participation through establishing ground rules, making process interventions and jointly reviewing the dynamics [30].

Author Contributions: P.L.C. and S.G.L.S. contributed to the study design, data collection, data analysis, writing and revising of the manuscript. All authors have read and agreed to the published version of the manuscript.

Funding: Petru L. Curșeu was supported in writing this manuscript by the Province of Limburg, The Netherlands, under grant number SAS-2019-00247.

Conflicts of Interest: The authors declare no conflict of interest.

\section{References}

1. Block, T.; Goeminne, G.; Van Poeck, K. Balancing the urgency and wickedness of sustainability challenges: Three maxims for post-normal education. Environ. Educ. Res. 2018, 24, 1424-1439. [CrossRef]

2. Yearworth, M. Sustainability as a 'super-wicked'problem; opportunities and limits for engineering methodology. Intell. Build. Int. 2016, 8, 37-47. [CrossRef] 
3. Lehtonen, A.; Salonen, A.; Cantell, H.; Riuttanen, L. A pedagogy of interconnectedness for encountering climate change as a wicked sustainability problem. J. Clean. Prod. 2018, 199, 860-867. [CrossRef]

4. Thollander, P.; Palm, J.; Hedbrant, J. Energy Efficiency as a Wicked Problem. Sustainability 2019, 11, 1569. [CrossRef]

5. Dronova, I. Landscape beauty: A wicked problem in sustainable ecosystem management? Sci. Total. Environ. 2019, 688, 584-591. [CrossRef]

6. Termeer, C.J.; Dewulf, A.; Biesbroek, R. A critical assessment of the wicked problem concept: Relevance and usefulness for policy science and practice. Policy Soc. 2019, 38, 167-179. [CrossRef]

7. Weber, E.P.; Khademian, A.M. Wicked Problems, Knowledge Challenges, and Collaborative Capacity Builders in Network Settings. Public Adm. Rev. 2008, 68, 334-349. [CrossRef]

8. Peters, B.G. What is so wicked about wicked problems? A conceptual analysis and a research program. Policy Soc. 2017, 36, 385-396. [CrossRef]

9. Coyne, R. Wicked problems revisited. Des. Stud. 2005, 26, 5-17. [CrossRef]

10. Roberts, N. Wicked problems and network approaches to resolution. Int. Public Manag. Rev. 2000, 1, 1-19.

11. Head, B.W. Forty years of wicked problems literature: Forging closer links to policy studies. Policy Soc. 2018, 38, 180-197. [CrossRef]

12. Gray, B.; Purdy, J. Collaborating for our Future: Multistakeholder Partnerships for Solving Complex Problems; Oxford University Press: Oxford, UK, 2018.

13. Fiorino, D.J. Citizen participation and environmental risk: A survey of institutional mechanisms. Sci. Tech. Human Values 1990, 15, 226-243.

14. Bolis, I.; Morioka, S.N.; Sznelwar, L.I. Are we making decisions in a sustainable way? A comprehensive literature review about rationalities for sustainable development. J. Clean. Prod. 2017, 145, 310-322. [CrossRef]

15. Reed, M.S. Stakeholder participation for environmental management: A literature review. Boil. Conserv. 2008, 141, 2417-2431. [CrossRef]

16. Fritz, L.; Binder, C.R. Participation as Relational Space: A Critical Approach to Analysing Participation in Sustainability Research. Sustainability 2018, 10, 2853. [CrossRef]

17. Curșeu, P.L.; Schruijer, S.G. Stakeholder diversity and the comprehensiveness of sustainability decisions: The role of collaboration and conflict. Curr. Opin. Environ. Sustain. 2017, 28, 114-120. [CrossRef]

18. Schruijer, S.G.L. Working with group dynamics while teaching group dynamics in a traditional classroom setting: An illustration of a systems-psychodynamic point of view. Team Perform. Manag. 2016, 22, 257-268. [CrossRef]

19. Schruijer, S. The psychology of interorganizational relations. In the Oxford Handbook of Interorganizational Relations; Cropper, S., Ebers, M., Huxham, C., Ring, P.S., Eds.; Oxford University Press: Oxford, UK, 2008; pp. 417-440.

20. Vansina, L.; Taillieu, T.C.B.; Schruijer, S.G.L. Managing multiparty issues: Learning from experience. In Research in Organizational Change and Development; Pasmore, W., Woodman, R., Eds.; JA1 Press: Greenwich, CT, USA, 1998; Volume 11, pp. 159-183.

21. Huxham, C.; Vangen, S. Ambiguity, Complexity and Dynamics in the Membership of Collaboration. Hum. Relations 2000, 53, 771-806. [CrossRef]

22. Jackson, M.; Stewart, R.A.; Fielding, K.S.; Cochrane, J.; Beal, C.D. Collaborating for Sustainable Water and Energy Management: Assessment and Categorisation of Indigenous Involvement in Remote Australian Communities. Sustainability 2019, 11, 427. [CrossRef]

23. Curşeu, P.L.; Schruijer, S. Cross-Level Dynamics of Collaboration and Conflict in Multi-Party Systems: An Empirical Investigation Using a Behavioural Simulation. Adm. Sci. 2018, 8, 26. [CrossRef]

24. Deutsch, M. A Theory of Co-operation and Competition. Hum. Relat. 1949, 2, 129-152. [CrossRef]

25. Johnson, D.W. Social Interdependence: Interrelationships Among Theory, Research, and Practice. Am. Psychol. 2003, 58, 934-945. [CrossRef] [PubMed]

26. Daly, M.; Silver, H. Social exclusion and social capital: A comparison and critique. Theory Soc. 2008, 37, 537-566. [CrossRef]

27. Holmes, J.G. Interpersonal Expectations as the Building Blocks of Social Cognition: An Interdependence Theory Perspective. Pers. Relatsh. 2002, 9, 1-26. [CrossRef] 
28. Borden, R.J. Psychological dimensions of sustainability: Minding the future from a human-ecological perspective. Curr. Opin. Environ. Sustain. 2017, 25, 45-49. [CrossRef]

29. Peter, C.; Swilling, M. Linking Complexity and Sustainability Theories: Implications for Modeling Sustainability Transitions. Sustainability 2014, 6, 1594-1622. [CrossRef]

30. Schruijer, S.; Vansina, L. Working across organizational boundaries: Understanding and working with the psychological dynamics. In Psychodynamics for Consultants and Managers: From Understanding to Leading Meaningful Change; Vansina, L., Vansina-Cobbaert, M.-J., Eds.; Wiley: London, UK, 2008; pp. 390-410.

(C) 2020 by the authors. Licensee MDPI, Basel, Switzerland. This article is an open access article distributed under the terms and conditions of the Creative Commons Attribution (CC BY) license (http://creativecommons.org/licenses/by/4.0/). 